- Patients often practise rituals according to their religion.

- These rituals often impact on the health and routine management of the dental patient.

- This article describes how the religion of Islam may affect the health and management of the CPD PAPER patient.

- The reader will be able to manage a Muslim patient with empathy and understanding at their convenience.

\title{
The management of the Muslim dental patient
}

\author{
S. Darwish ${ }^{1}$
}

There are aspects of the practice of the religion of Islam that have some relevance to receiving dental treatment. This article aims to provide dentists with background knowledge of normal practices which may affect the treatment offered. The author does not attempt to inform the reader about Islam, but to assist the dentist in the management of a Muslim patient. Much of the content of this article describes how to manage a patient who is fasting during the Islamic month of Ramadan. Ramadan takes place this year in early October, lasting for 29 or 30 days. During Ramadan patients may present to dentists with the signs and symptoms described in this article.

A Muslim is an individual who practises the religion of Islam; there are now almost 2 million Muslims living in the UK, around $3 \%$ of the total British population. ${ }^{1}$

The basis of the religion revolves around its 'five pillars' which are belief, prayer, fasting, giving of charity, and pilgrimage. The majority of the practice of the religion arises from this basic structure and may have relevance to dentistry.

\section{BELIEF}

The basic belief of a Muslim is in God (Allah). A Muslim patient therefore typically receives information about disease and their health, including dental disease, with the belief that their fate is determined and dictated by God. Accordingly, a commonly used phrase used by a Muslim when

\footnotetext{
${ }^{1}$ Specialist Surgical Dentist \& Staff Grade Surgeon, Department of Oral \&t Maxillofacial Surgery, Guy's King's \& St Thomas' Dental Institute, Caldecot Road, London SE5 9RW

Correspondence to: Dr Samy Darwish

Email:samydarwish@hotmail.com
}

\section{Refereed Paper}

Accepted 15 June 2005

doi: $10.1038 /$ sj.bdj.4812807

๑ British Dental Journal 2005; 199: 503-504 discussing health issues such as prognosis and treatment outcomes is 'insha'Allah' which means 'God willing'.

\section{PRAYER}

A Muslim prays five times a day following calls to prayer at specific times of the day, which vary according to changing daylight hours. Most Muslims will carry out the prayer at some time between one call for prayer and the next although some will wish to pray immediately after the call. When making appointments for dental treatment, patients may wish to check their timetable so that they do not clash with prayer times. Friday lunchtime prayers are those when many congregate at the mosque for a communal gathering. Friday afternoon appointments are therefore often inconvenient.

\section{FASTING}

During the Islamic month of Ramadan, a Muslim will fast. The individual will ingest no food or drink, including water, from dawn to sunset for each day of the month.

There is an increase in the concentration of sulphur containing compounds present in the oral cavity with time when a patient is fasting ${ }^{2}$ causing a marked mal- odour, which may be misdiagnosed as being associated with poor oral hygiene or oral disease. The odour may reduce with debridement with dentifrice or when the individual breaks their fast. ${ }^{2}$

A patient presenting at the dental practice during a fast may show signs of irritability or a degree of cognitive impairment. This has been shown to be associated with the lack of intake of addictive substances such as nicotine and caffeine. ${ }^{3}$ Individuals who are fasting during daylight hours attempt to compensate for the lack of intake of food during the night. A common practice includes waking to consume a meal before sunrise. The sleep disturbance together with the lack of caffeine as a central nervous system stimulant may result in tiredness, irritability and lack of concentration. ${ }^{3}$ Any drop in a patient's blood glucose is small due to compensatory liver gluconeogenesis and there is no evidence of hypoglycaemia in normal subjects. ${ }^{4}$

Some individuals may perceive that some other occurrences break their fast. The administration of local anaesthetic for example may be interpreted as an intake of fluid into the body. The water spray from a handpiece may be inadvertently swal- 
lowed and so a patient may refuse treatment while fasting. Some individuals try to not even swallow their own saliva and some perceive placement of a foreign object in their mouth, even a toothbrush, as breaking of their fast. Such individuals are likely to refuse a clinical oral examination.

A practising Muslim may not necessarily be fasting. Patients who have a medical condition [such as diabetes] who would endanger themselves by fasting, are exempt from the ritual. Expectant mothers and menstruating women are also exempt. Even those who are suffering from an acute condition need not fast on that day. A patient that is suffering from an acute dental condition may be advised to break their fast if urgent dental treatment is necessary.

The dentist may wish to offer the Muslim patient appointments which are convenient to their rituals. If appointments can be postponed until after Ramadan, this would be advisable, otherwise late afternoon or evening appointments, after sunset could be offered so that the patient presents already fed.

\section{CHARITY}

Annually, a practising Muslim donates a percentage of their savings to charity. A Muslim will therefore need to clear monies owed before calculating this figure, including finances as part of their dental treatment.

\section{PILGRIMAGE}

A Muslim carries out a pilgrimage to Mecca in Saudi Arabia at least once in their life. A Muslim must clear all debts before embarking on a pilgrimage, therefore a dentist may assist a Muslim patient by informing them of any outstanding monies if a pilgrimage is imminent.

Muslims returning from a pilgrimage may be considered a risk for cross-infection of respiratory borne diseases. The pilgrimage attracts over two million Muslims from all over the world, and overcrowding provides ideal conditions for the transmission of infectious diseases. ${ }^{5}$ Cross-infection control measures for practice staff and patients must be implemented.

\section{OTHER RITUALS OF RELEVANCE TO DENTISTRY}

Some Muslims continue to carry out a traditional method of oral hygiene. The

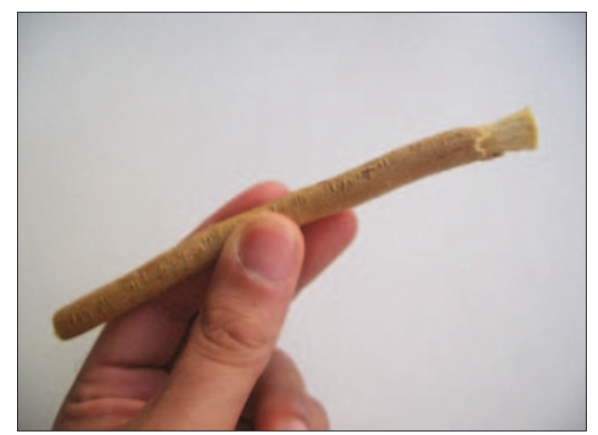

Fig. 1 The Miswaak

'miswaak' is a small twig with a frayed end from the plant Salvadora persica which is used to rub against the surfaces of the teeth (Fig. 1). Toothpaste is not applied. The twig is reported to have some antimicrobial and plaque inhibitory effects. ${ }^{6} \mathrm{~A}$ patient using this method of oral hygiene may present with gingivitis and periodontitis as it is less efficient than toothbrushing in plaque removal. ${ }^{7}$ A distinctive yellow stain to the teeth may also be present as well as dental caries, although anti-cariogenic properties are reported and ascribed to the fluoride content of the miswaak. ${ }^{8}$ The twig is also abrasive therefore patterns of toothwear may be evident ${ }^{9}$ as well as gingival recession. ${ }^{10}$

Some Muslims dress in a particular way. Many Muslim women cover their hair and neck with a head-scarf called a 'hijab', which they wear in the presence of the opposite sex. It may pose a problem for dentists as it may interfere with a required extra-oral examination (Fig. 2). Other women take this dress even further, covering their face, which poses obvious problems for the dentist in terms of access to the oral cavity. Careful consent is required in examining and providing treatment for such patients. Some may welcome an offer

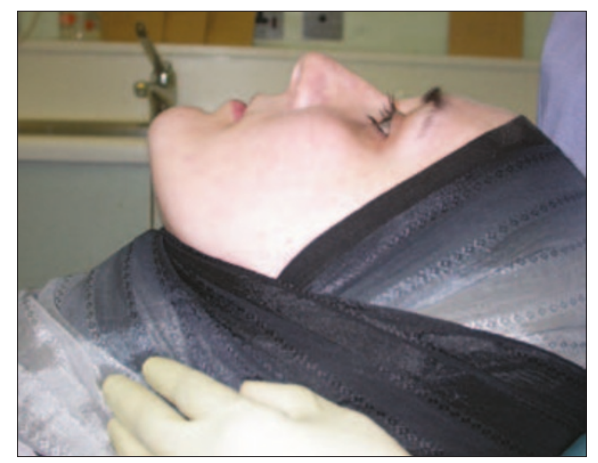

Fig. 2 Difficulty in extra-oral examination of a patient wearing hijab of treatment provided by a female dentist and assistant; others may consider it appropriate to remove the scarf to allow medical intervention including dental treatment.

Some Muslims have issues with animal products. The intake of porcine products is strictly prohibited therefore a Muslim is likely to object to the use of any dental or medical product which contains porcine material. Many Muslims insist that the intake of other animal products need the animal to be sacrificed in a certain way and therefore may prefer the use of synthetic products only. Most Muslims consider alcohol to be prohibited and therefore products containing alcohol may be refused by a patient.

Muslim men avoid wearing gold as jewellery. This may be extended to using gold for dental restorations. Careful consideration must therefore be taken when selecting a suitable dental material for restoration and the patient's wishes respected accordingly.

As with any religion, the practice of Islam varies according to the individual's interpretation. Rituals described are not necessarily normal for every practising Muslim but are examples of practices that may be carried out. A dentist should be aware of any religious and cultural rituals that impact on the management of the patient in order to treat the patient with empathy and understanding.

1. The World Factbook 2004. Central Intelligence Agency, 2004.

2. Tonzetich J. Direct gas chromatographic analysis of sulphur compounds in mouth air in man. Arch Oral Biol 1971; 16: 587-597.

3. Kadri N, Tilane A, El Batal M et al. Irritability during the month of Ramadan. Psycho Med 2000; 62: 280-285.

4. Beshyah SA, Sherif I. Diabetes during Ramadan and Haj. In Lakhdar A A, Gill G V (eds). Diabetes in the Arab world. pp 225-240. Cambridge: FSG Communications Ltd, 2005.

5. Wilder-Smith A, Barkham T M S, Earnest A et al. Acquisition of W135 meningococcal carriage in Hajj pilgrims and transmission to household contacts: prospective study. Br Med J 2002; 325: 365-366.

6. Akpata ES, Akinrimisi E O. Antibacterial activity of extracts from some African chewing sticks. Oral Surg Oral Med Oral Path 1977; 44: 717-722.

7. Norton M R, Addy M. Chewing sticks versus toothbrushes in West Africa. A pilot study. Clin Prev Dent; 11: 11-13.

8. Touyz L Z G, Khan M N, Goga E. A note on the Miswaak. Diastema 1985; 13:34-36.

9. Radentz W H, Barnes G P, Cutright D E. A survey of factors possibly associated with cervical abrasion of tooth surfaces. J Perio 1976; 47: 148-154.

10. Eid M A, Selim H A, Al-Shammery A R. The relationship between chewing sticks (Miswaak) and periodontal health. III. Relationship to gingival recession. Quint Int 1991; 22: 61-64. 